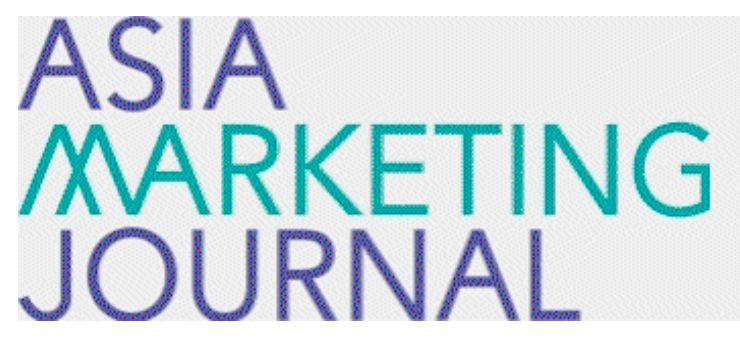

ASIA MARKETING JOURNAL

Volume 14 | Issue 3

Article 5

10-30-2012

\title{
Why Genuine Luxury Brands Are Consumed? Counterfeits? Examining Consumer Identification
}

Hyun Suk Suh

Follow this and additional works at: https://amj.kma.re.kr/journal

Part of the Marketing Commons

\section{Recommended Citation}

Suh, Hyun Suk (2012) "Why Genuine Luxury Brands Are Consumed? Counterfeits? Examining Consumer Identification," Asia Marketing Journal: Vol. 14 : Iss. 3 , Article 5.

Available at: https://doi.org/10.53728/2765-6500.1490

This Article is brought to you for free and open access by Asia Marketing Journal. It has been accepted for inclusion in Asia Marketing Journal by an authorized editor of Asia Marketing Journal. 


\section{Why Genuine Luxury Brands Are Consumed? Counterfeits? Examining Consumer Identification}

Hyunsuk Suh*

Owing to increased number of luxury brand users, both genuine and counterfeit luxury product consumption continues to increase every year. Luxury brand is defined as use or display of a particular branded products which brings the ownership prestige apart from its functional utility (Grossmand and Shapiro 1988). Some luxury brands have imitations sold in marketplace due to their popularity. These imitations or counterfeits have been jumping on the bandwagon of the upturn in sales of their originals. The purpose of our study is to understand consumer's underlying motives to consume luxury brands, genuine and or counterfeits. To do this, we propose functional theories of attitudes, decision-making styles, and life attitudes to form the determining causes for different consumption choices of luxury brands: genuine brands, counterfeit brands, both genuine and counterfeit brands, and no consumption on luxury brands types. In proposed causal pathways, we examine moderated effects of socio-psychological factors to further investigate if consumer profiles would exert influences in causal relationships. From the existing theories of functional attitudes: value-expressive and social-adjustive attitudes, we developed and introduced a new measure of rationality-consumptive attitude. From the existing eight decisionmaking characteristics of consumer styles inventory(CSI), three measures of high-quality, hedonicshopping, and price-shopping styles were primarily applied in the study along with newly introduced measure of "high-price' being added, which makes four total. Seven life attitude measures of life purpose. life control, will to meaning, goal seeking, future mean to fulfill, life satisfaction, and religiosity were applied. Finally, such socio-psychological measures as age, gender, marital status, income, and age-gap between couples were assumed to function as moderators. With 430 valid study samples, ages from 20 s to 50 s, with more females(316) than males(114). with average personal possessions of 5 genuine and 9 counterfeit luxury brands, we conducted questionnaire survey. Results indicated that social-adjustive function is totally disappeared in the relationship due to current social trend of widespread consumptions on both genuine and counterfeit brands which in turn, make consumers feel less special on wearing or carrying them unlike in the past. Self-expressive function and rationality-consumptive functions act as strong catalysts for genuine brand consumption and counterfeit brand consumption, respectively. On consumers decision-making styles, high-price sublation is the most powerful indicator anticipating

\footnotetext{
* School of Business Administration, College of Business \& Economics, Chung-Ang University(hssuh@cau.ac.kr)
} 
counterfeit consumption, even more powerful than personal incomes. In life attitude, the overall model fit was not validated, and only life control and life satisfaction are proven to be significant on both genuine and counterfeit product consumptions. Employment of socio-psychological factors in the model improved understanding of users further. Young consumers tend to go for genuine products over counterfeits. Consumers in different income groups: low, medium and high, all significantly consume genuine products for reasons of different decision-making styles. The results indicated that consumers whose personal disposition is predisposed to consume products in the form of reflection of his or her personality, go only for genuine brands for quality reason. while consumers who rationally consume products for its function or usability, go only for counterfeits for high-price sublation reason. Meanwhile, both product users support for high-price orientation who are not well off.

Key words: genuine brand, counterfeit brand, self-expressive function, social-adjustive function, rationality-consumptive function

\section{Introduction}

Lately, luxury brands importation has been dramatically increased in Korea. Part of the reason is ascribed to free trade agreement between Korea and EU countries, which has accelerated the unconditional aspiration of luxury brand lovers. The figures from Korea Customs Service indicated bags, watches and clothing are the leading luxury imports these days. The figures on the amount of imports on these items in 2011 alone indicated way over 12 billion dollars compared to 9 billion dollars in previous year. An item by items basis, bags has been increased by $31 \%$ in 2011 , watches by $13.4 \%$, and clothing by $21.6 \%$, respectively. However, the increment of dollar figure of luxury imports is not linearly proportional to that of volumes imported. This explains either the unit price for imports has been raised and or higher-priced brands are being imported. The evidence on this proposition is supported by the report from Korea Customs Service in which, the average unit cost(total import volume/total import amount) for bags is $\$ 544.47$ raised from $\$ 426.81$ in previous year, for watches is $\$ 152.65$ from $\$ 121.28$, and for clothing is $\$ 273.34$ from $\$ 233.75$, respectively. Meanwhile, the counterfeit luxury brands have been riding piggyback on the rapid growth of luxury brands. Twice as many fake watch imports have been disclosed by the Korean Customs Service in 2011, compared to previous year. Korea Chamber of Commerce and Industry conducted research on luxury brands purchase on people over 20 years of age. The result indicated that $22 \%$ out of 704 participants have prior exposure to counterfeit luxury brands consumption. 
The $67.7 \%$ of these people intentionally look for and purchased counterfeits. About half of female participants, ages between 20s to 30 s have more than two counterfeit luxury brands, especially bags such as Louis Vuitton. Chanel, and Gucci in the order of popularity(Herald News 2011.12.08).

Here, the question lies what makes consumers to purchase luxury brands or counterfeit luxury brands? Researchers defined luxury brands as use or display of a particular branded product such as Armani, Bvlgari, Chanel, Gucci, and Louis Vuitton(Dubois and Paternualt 1995) which brings the ownership prestige apart from its functional utility (Grossman and Shapiro 1988). The luxury brands can act as symbolic tool which displays the wealth and high socioeconomic status of its owners to other members of society (Barnett 2005: Phau et al. 2009). Dubois and Duquesne(1993) suggested that consumers purchase luxury brands primarily to satisfy their appetite for symbolic meaning of status label or image associated with the product, often overly valued than product per se. Therefore, by consuming luxury brands, one can express such value that are normally accepted, recognized, and admired by the beholder. Nia and Zaichkowsky (2000) stated consumers purchase luxury brands to fulfill their psychological needs of portraying specific social class which reflects self-image, which in turn, will enhance their self-concept. Consumers purchase these products to let other people know that they can afford such high prices of famous brands.

Counterfeit luxury brands(hereinafter, the counterfeit luxury brands will be referred to as counterfeit brands or just counterfeits) is by definition, illegal reproduction of products that typically possess high brand value, in which they are distinguished as illegal, low-priced, and often lower-quality compared to genuine brands(Lai and Zaichkowsky 1999). Counterfeiting can be deceptive or nondeceptive(Grossman and Shapiro 1988). Deceptive counterfeiting occurs when consumers purchase counterfeit brands without knowing it. In case of nondeceptive counterfeiting. consumers are well aware of what they purchase is counterfeit product. The nondeceptive form of counterfeiting prevails over deceptive counterfeiting especially in the areas of bags, watches, and clothing these days. In fact, most consumers who consume counterfeit bags, watches, and clothing intentionally seek for these items due to its low price, and not so low resemblance compared to genuine brands in terms of product functions. Indeed the quality of counterfeit brands had been notably improved recently, almost approaching the level of genuine brands. This is attributable to the fact that many luxury brand marketers wanted to reduce the production cost so that they depend substantial portion of the product tangibles on outsourced manufacturing. Some factories that produce outsourced luxury products add 'extra shifts' to their production runs, so that they can distribute them as top notch counterfeits elsewhere with 
higher margins than that of the major accounts (Phillips 2005). Although the counterfeits are considered as constructed with inferior raw materials, they are often produced with same design, specification, and finishing touch(Parloff, 2006). Prior studies have found that consumers who purchase counterfeits are of lower social status(Bloch et al. 1993), and their likelihood of consuming a counterfeits is inversely related to the price of genuine luxury brands(Albers-Miller, 1999).

Some studies investigate consumer attitudes in pursuing luxury brands. The research on functional theories of attitudes(DeBono 1987; Katz 1960: Shavitt 1989: Smith et al. 1956) introduced the idea in which personal attitudes serve important social functions such as allowing self-expression (value-expressive or self-expressive function/attitude) and facilitating self-presentation (social-adjustive function/attitude). Attitude serving self-expressiveness supports consumers to deliver their beliefs, attitudes, and values to others(Katz 1960). It means that consumers hold self-expressive attitude toward product, selfexpression or reflection of self-image is a significant motivator for product consumption. Attitude serving social-adjustive function supports people to maintain relationship with others(DeBono 1987: Smith et al. 1956). When consumers hold social-adjustive attitude toward product, they tend to be motivated to consume it to gain social approval. According to Shavitt(1989), consumer's attitude toward luxury brands can serve both self-expressive and or social-adjustive functions because some people want to represent his/her personality(self-expression), while others want to reflect his/her status symbol(self-presentation). This as a base, Wilcox et al. (2009) suggested that self-expressive attitude toward luxury brands will motivate consumers to prefer genuine luxury brands. This is because self-expressive attitude triggers intrinsic aspect of product such as qualityrelated reasons. Compared to self-expressive attitude, the social-adjustive attitude toward luxury brands is associated with greater preference for counterfeit brands as long as they have high resemblance to genuine brands in terms of product form(i.e. genuine brand look-alike appearance). This is because it works on the level of image-related motive rather than function or quality of product. For these consumers, the consumption purpose lies primarily in setting social status or symbol rather than intrinsic aspects of product, thereby lesser quality on product function is endurable.

At this point, a question arises, would socialadjustive attitude always arouse consumption urge for counterfeits, just like self-expressive attitude to genuine brands? If so, when consumer's attitude serves social-adjustive function, the goal of gaining social approval has to be salient, while the goal of expressing their beliefs, and value has to be kept in silence. When consumer's attitude serves self-expressive function, it should be the other way around. On other consideration, although such attitudes will con- 
sistently guide consumers propensity on the product they consume with their central beliefs, intentions, and motives, but when time comes for actually have to choose between the genuine brands and counterfeits, their preference on either choice can vary regarding the product per se. To provide evidence on this query, the current study testifies different attitudes as primary motivators on different consumption choice of luxury products as first study objective.

Along with the studies of functional attitude theories, this research further seeks for motives on product choice of individuals. Individuality in consumers behavior in selection of the product choice is one of the major topics in consumerinterest studies. Here, the underlying assumption is that consumers approach market with certain decision-making styles on their own. Although variety of factors influences consumer decisionmaking in product selection, these styles significantly affect consumers' final action(Bettman 1979: Jacoby and Chestnut 1978: Maynes 1976: Miller 1981: Sproles 1979: Thorelli et al. 1975). As part of consumer-interest research. Sproles and Kendall(1986) introduced consumer styles inventory(CSI) in an attempt to conceptualize and measure consumer' decision-making styles. They identified eight basic mental characteristics for consumer decision-making, each independently represents important mental approaches to consumption which characterize an approach toward choosing product from alternatives. Study revealed consumers show different decision-making styles for different product category, with permissible variation in individual personalities. The topic of consumer decisionmaking style is centrally important in understanding underlying motives on consumption choice for both genuine brands and counterfeits in our study. Genuine luxury brands are characterized as expensive, and exclusive which brings prestige on the owner, whereas counterfeits are illegal, low-priced, and often lower-quality replicas of products that typically possess high brand value(Lai and Zaichkowsky 1999). Therefore, depending on different product characteristics in each category possesses, the investigation of couplings of individual's decision-making styles on consumption choice on these products is another objective of the study.

Last but not least, this research explores if socioeconomic variables have effects in different consumption choice. Vida(2007) studied various socioeconomic and socio-psychological characteristics involved in consumers' inclination to purchase counterfeit products, such as gender, age, level of education. marital status, income, and religiosity. Study revealed gender and religiosity have significant effect on consumers' counterfeit product purchase. Previous studies investigated the impact of "income' on the product choice, such as low income or low social status is positively related with purchase intention or favorable attitude toward counterfeits(Albers-Miller 1999: Bloch et al. 1993: Dubois and Duquesne 1993: Kim 2011: Lee 2004: Penz and Stottinger 2005:). 
Rephrased, the status goods are associated with greater expenditure on personal possessions which in turn, has strong of association with high income level. As a part of study objectives, the socio-psychological factors will be explored to amplify better understandings on what goes underneath the consumers' preference on consumption choice of luxury products.

\section{Theory and Hypotheses}

\subsection{Functional Theories of Attitude and Different Consumption Types of Luxury Brands}

The demand side of studies indicated that people make inferences about others based on the possessions they have, and luxury goods or status goods are the ones for which ownership of them can bring prestige on the user. Especially for those publicly self-conscious individuals who concern about physical impression they make on others, would like to gain social prestige or status by consuming luxury brands(Grossman and Shapiro 1988: Bushman 1993: Dubois and Duquesne 1993: Dubois and Paternault 1995). Since the special characteristics of luxury brands are prestige and rarity, not everyone who desire for luxury brands can afford its high price. Therefore the market for counterfeit brands which supplies authentic brands look-alike at lower price, meets consumers' desire for genuine luxury brands(Hoe et al. 2003: Penz and Stottinger 2005). As referred to earlier, there are two types of transactions involved in counterfeiting: deceptive and non-deceptive counterfeiting (Grossman and Shapiro 1988). Deceptive counterfeiting is identified as a situation in which consumers are not aware of purchasing a counterfeit product at the time of purchase. Such products as automotive parts electronic products and even pharmaceuticals and medical devices can belong in this category. The non-deceptive counterfeiting is a situation in which consumers are fully aware that they are purchasing counterfeit products at the time of purchase. Such products as bags, watches, and fashion items belong in this category. Non-deceptive counterfeit brand is even claimed to have positive effects on the market such as building brand awareness(Shultz and Saporito 1996) and increase snob value for genuine brand(Barnett 2005). From the view point of supplier of non-deceptive counterfeit products, consumers are fully aware and even intentionally looking for these products (Stipp 1996). Since the quality of counterfeits has improved over the years and it is becoming more difficult for consumers to distinguish between counterfeit and original ones, counterfeiting can help customers on purpose, to have their dream become reality at lower price(Gentry et al. 2006). Though arguable, this view point is agreeable in some sense. In this study, we exclusively define counterfeit luxury brand as 'non-deceptive 
counterfeit brand' in which buyers recognized that the product is not authentic due to specific information signals such as relatively lower price, purchase location, and raw materials that constitute product(Chakraborty et al. 1997: Gentry et al. 2006).

To understand underlying motives for both luxury brand and counterfeit brand consumption further, just other than what appears outwardly, we employed functional theories of attitude. The attitude side of researches(Smith et al. 1956: Katz 1960: DeBono 1987; Shavitt 1989: Wilcox et al. 2009) introduced different personal attitudes such as self-expressive and socialadjustive attitudes work on different levels for both luxury and counterfeit brands consumption. From the standpoint of definition, social-adjustive attitude signifies that luxury brands consumption occurs in situation when individuals want to gain social approval, their social goal of projecting particular images in social settings. The selfexpressive attitude occurs in situation when individuals want to communicate their central beliefs, attitudes, and values to others. When consumers hold self-expressive attitude they consume products in the form of self-expression which reflects his or her personality (Hoe et al. 2003: Penz and Stottinger 2005). The socialadjustive attitude motivates individuals to consume luxury brands for the purpose of projection of image or outward appearance-related reasons. Therefore, compared to self-expressive attitude. social-adjustive attitude works more favorably on genuine luxury look-alike product(i.e, counterfeits) (Wilcox et al. 2009).

Snyder and DeBono(1985) suggested that self-expressive attitude serves not only communication of personality to others, but also intrinsic nature of product such as quality and reliability(i.e. product function). Taken from the proposition of Snyder and DeBono(1985), we assume two different semantic connotations can stem from a single domain of self-expressive function. One works as a vehicle to project self-image outwards, while the other pertains to usability on functional attributes of product. Thus, we decided to break down self-expressive function into two domains of personality expression and usability on functional attributes, named it as 'self-expressive function(or attitude), and 'rationality-consumptive function(or attitude) respectively. Although a new term, rationalityconsumptive function is derived from the original 'self-expressive function,' it is assumed to work for counterfeit luxury brands consumption as well. Consumers purchase decision involves a function between gains from owing and using the product and cost of obtaining it. If consumers' rationale leans toward 'cost' side of the function(i.e. sensitivity in amount of money he/she has to spend to get genuine product while he can also get counterfeits which has identical product form to that of genuine brand, yet available only at half the price of the original), the consumption preference shifts to counterfeit luxury brands. If consumer's rationale leans 
toward 'gain' side of the function(i.e. belief on no matter what, the genuine products have far superior durability, quality, designs, molds, specification, and so forth, than that of counterfeits), the consumption preference shifts to genuine luxury brands. Again, Wilcox et al. (2009) suggested that self-expressive attitude toward luxury brands will motivate consumers to prefer genuine luxury brands, due to quality-related reasons. This means however high the degree of resemblance of counterfeits gets, to that of genuine products, even exactly the same level as they are manufactured from the same plant which produces genuine products as foresaid, consumers will feel class distinctions between the two. To sum it up, self-expressive attitude toward luxury brands motivates consumers to prefer genuine luxury brands, while social-adjustive attitude motivates consumers to prefer counterfeit luxury brands. The new born rationalityconsumptive attitude motivates consumers to prefer both consumption choices depending on the situation.

Since the study investigates different attitudes on different consumption types of luxury brands, we define different consumption types into following category: genuine luxury brand users, counterfeit luxury brand users(i.e. non-deceptive counterfeit brand), non-users(those people who do not consume luxury brands at all(no-brand consumption type, and both genuine and counterfeit luxury brand users(hereinafter, both genuine and counterfeit luxury brand users will be referred to as "both-users,' also both genuine and counterfeit luxury brands will be referred as 'both-products'). To test this, standard of comparison among user types(i.e. different consumption types) needs to be set. The study sets 'non-users' as reference point to make comparisons with rest of the other user types. This is because primary goal of this research investigates differences in attitudes, motives, and socio-psychological characteristics among different user types, except for the 'non-user' type. Nonusers work as a "control group" to minimize any contaminating factors(i.e. to allow the alternative explanations to be rejected) that may slip in the process of comparison among different user types. The non-users naturally occur in our sample population, but they are not the part of study objectives. In other words, we do not have interest on non-users, as to "what makes non-users not consume luxury brands?" Therefore, non-user group can properly work as control group who does not receive the treatment(i.e. different types of luxury brand consumption). With the non-user group set as the reference point, the following hypotheses are predicted:

H1: Compared to non-users, the genuine luxury brand users are highly likely to be served by self-expressive and rationalityconsumptive attitudes.

H2: Compared to non-users, the counterfeit luxury brand users are highly likely to be served by rationality-consumptive and 
social-adjustive attitudes.

H3: Compared to non-users, the both-users are highly likely to be served by selfexpressive, rationality-consumptive, and social-adjustive attitudes.

\subsection{Consumers' Decision-Making Styles and Different Consumption Types of Luxury Brands}

Prior studies on consumers' behavior in selection of the product choice assume that consumers are thought to approach the market with certain basic decision-making styles. Consumer decisionmaking style is a mental orientation of characterizing a consumer's approach to making product choice. According to consumer literature. there are three ways to characterize consumer styles: psychographic lifestyle approach, consumer typology approach, and consumer characteristic approach(Bettman 1979: Jacoby and Chestnut 1978: Maynes 1976: Miller 1981: Sproles 1979: Thorelli et al. 1975). Of these, consumer characteristics approach puts focus on cognitive and affective orientation being specifically connected to consumer decision-making (Sproles 1985: Westbrook and Black 1985). Sproles and Kendall(1986) introduced a method to measuring characteristics of consumer decision-making styles. The method contains eight decision-making characteristics of CSI(Consumer Styles Inventory) and format for reporting an individual's characteristics, called PCS(Profile of Consumer Style).
The study identified eight independently significant mental approaches in decision-making to consumers' product consumption: high-quality consciousness, brand consciousness, novelty-fashion consciousness, hedonistic shopping consciousness, price shopping consciousness, impulsiveness, confusion from over-choice, and habitual consumption.

Current study adopts these mental characteristics as a base for our consumer decisionmaking styles on different consumption types, with one exception: brand consciousness. Current study primarily explores consumption of luxury brands only. Therefore, consumption of products that are 'brand-oriented or not' as part of decisionmaking characteristics is not appropriate for the study context. Instead, we replaced it with intrinsic aspect of product: a price. Price here refers to "high-price orientation,' meaning consumers prefer high priced product due to its quality or other reasons the highly priced products flaunt to consumers. High-price orientation is positively correlated to genuine luxury products. Obviously it's the single most prominent distinction from the counterfeits. Again, standard of comparison among user types is set at nonuser' for the purpose of comparison with rest of the groups. We assume that genuine luxury brand users are highly connected to high quality consciousness, hedonistic shopping consciousness, and high-price orientation. Hedonistic shopping consciousness involves fun or pleasure in shopping process. We believe this feeling of "pleasure' works positively on genuine product con- 
sumption rather than on counterfeits. Negative feelings such as guilt, uneasiness, or disclosure can involve in the process of counterfeit consumption, in which they are nowhere near the feelings of pleasure. We assume the influences on following decision-making styles of impulsiveness, confusion from over-choice, and habitual consumption are meager on consumers' choice between genuine luxury and counterfeit luxury goods, thereby not included in hypotheses forming. However these items do participate in data collection and data analyses. Formally, we predict following hypotheses:

H4: Compared to non-users, the genuine luxury brand users are highly likely to be served by such decision-making styles of consumer as high quality consciousness. hedonistic shopping consciousness, and high-price orientation.

H5: Compared to non-users, the counterfeit luxury brand users are highly likely to be served by such decision-making style of consumer as price shopping consciousness (value for money).

H6: Compared to non-users, the both-users are highly likely to be served by such decision-making styles of consumer as high quality consciousness, hedonistic shopping consciousness, high-price orientation, and price shopping consciousness (value for money).
Vida(2007) studied various determinants on consumers disposition to purchase non-deceptive counterfeit products. Socioeconomic and sociopsychological characteristics such as gender, age, level of education, marital status, income. and religiosity were investigated. Although study revealed only gender and religiosity showed significance, this approach becomes a crucial part of our research. Studies on ethical behavior models suggest that factors endemic to consumers such as age, gender, education, marital status, income, as well as religious beliefs have effects on person's ethical dilemmas(Al-Khatib et al. 2004: Dubinsky et al. 2005: Ferrell and Grisham 1985: Simpson et al. 1994: Stoettinger and Penz 2003). Furnham and Valgeirsson(2007) studied the effect of life values and materialism of consumers on buying counterfeit products. They found married couples are more likely to purchase counterfeits. These as a base, we postulate, socio-psychological constructs are potential candidates with qualifications in understanding why consumers consume different types of luxury brands. For instance, following what-if-scenario can be envisaged. "Do elders want genuine brands more than counterfeits?" A follow up question could come as, "if so, under why would they prefer genuine brands over counterfeits?" One of the possible responses would be, "Elders would want genuine brands more than counterfeits for high-quality and high-price reasons." Regardless of such response making sense or not, from the scenario, it is quite possible that consumers' 
decision making styles entangle with sociopsychological characteristics and different consumption types. Considering the fact that the causal relationship already exists between consumers decision making styles and different consumption types of luxury brands, the sociopsychological characteristics take responsibility as moderators.

We select age, gender, marital status, income as major influencers. In addition to consumer's physical age being important indicator, we introduced the idea of "age gap" between couples regardless of their marital status as significant an indicator. For example, luxury products are often served as presents for important dates or anniversaries on couples or gatherings of close friends. If not in all of personal luxury possessions are from significant other, couple exchanges assumed to take significant portion of personal luxury possessions. We assume it's worthy of look into whether 'age gap' between couples do matter in consumption choice between genuine and counterfeit brands. It is that bigger the age gap between couples will result in higher the consumption of genuine brand compared to couples with little age gap. This is under the assumption that they are involved in more of formal type of relationship compared to couples with little age gap. To sum it up. this study investigates moderating effects of age, gender, marital status, income, and age gap between couples in the causal relationship between consumers' decision making styles to different consumption types. Following assumptions are expected: consumers with high in age want genuine brands for quality and high-price reasons: women want genuine brands for hedonistic reason: married couples want counterfeit brands due to value for money (price-shopping consciousness) reason, while singles want genuine brands for quality or hedonic reasons: high-income earners want genuine brands for quality reason, while lower-income earners want counterfeits for hedonic reason: and couples with big age gap consume genuine brands for quality and hedonic reasons, while couples with little age group consume counterfeits for value for money reasons (under the assumption that couples with close in age is less likely to feel uneasy on counterfeit consumption compared to couples with big age gap(i.e. less of formal relationship)).

H7a: Compared to non-users, the genuine luxury brand users are highly likely to be served by the moderating effects of such socio-psychological indicators as high in age, female gender, singles in marital status, high income, and high age gap between couples, on the causal relationships between consumers' decision making styles to different user types of luxury brands.

H7b: Compared to non-users, the genuine luxury brand users are highly likely to be served by the moderating effects of such socio-psychological indicators as 
low in age, male gender, married in marital status, low income, and low age gap between couples, on the causal relationships between consumers' decision making styles to different user types of luxury brands.

\subsection{Life Attitudes and Different Consumption Types of Luxury Brands}

The literature on subjective well-being(SWB), which covers happiness, morale, life satisfaction, happiness, and positive affect in living are examined under the assumption that these motivate human actions in various different ways (Diner 1984). Since psychosocial features of people on SWB are suggested by Wilson(1967), which are characterized as "happy person emerges as a young, healthy, well-educated, wellpaid, extroverted, optimistic, worry-free, religious, married person with high self-esteem, high job morale, modest aspirations, of either sex and of wide range of intelligence," studies on defining well-being have begun forest fire of growth. Shin and Johnson(1978) introduced a term life satisfaction' and defined it as person's quality of life according to his chosen criteria. It is important to note that judgment on how satisfied person is with his present state of affairs is determined by the standard of comparison which each individual sets for him/herself(Diner 1984). As part of the study, attitudes towards life have been explored by Reker and Peacock
(1981) which is based on the study of purpose of life(PIL), in an attempt to assess degree of existential meaning, purpose of life and the strength of motivation in human actions. The life attitude profile(LAP), a multidimensional instrument to assess attitudes toward life, is developed not only to understand individual's attitudes on life but in an attempt to practical applications in real life situations. According to authors the LAP as a practical tool which appears suitable for application to such diverse situations as adolescent suicidal tendencies, recidivism among criminal offenders, underachievement in college students, job satisfaction in industry, aspects of aging such as retirement, and event to acceptance of death and dying (Reker and Peacock 1981). The current study follows suggestions of Reker and Peacock(1981) to apply LAP constructs to assess if life attitude profiles can make influences on different consumption choice of luxury brands.

LAP consist of seven factors: life purpose, existential vacuum, life control, death acceptance, will to meaning, goal seeking, and future meaning to fulfil. Life purpose is a measure on fulfillment and meaningfulness of life. Existential vacuum means the amount of tension or frustration in life. Life control represents freedom to make all life choices, and the perception of internal control of life events. Death acceptance dimension reflects a lack of fear and anxiety about death and dying. Will to meaning is a measure of effort to find meaning 
in personal existence, and appreciation of life. Goal seeking reflects the desire to achieve new goals in the future, and to search for new and different experiences. Finally, future meaning to fulfil is a measure of future fulfillment, the acceptance of future potential, and positive expectations of one's future life(Reker and Peacock 1981). When employing LAP scales in the study, we assumed the measure of "existential vacuum' is not tapping with construct's domain. The amount of tension and frustration in life is connected with consumption choice between genuine luxury brands and counterfeits? Therefore it is exempted from the study. The measurement construct of 'will to mean' in LAP study partially refers to the surveys of DDB Worldwide Communications Group. DDB, an acronym of founder's initials is a highly ranked worldwide advertising agency who conducted questionnaire survey on their customers of their daily life styles. The questionnaire contains 389 questions which include all areas of human lifestyles. Along with LAP scale, we adopted 'satisfaction with life scale(SWLS)' suggested by Diener et al.(1985). This scale was developed on the idea that in order to understand life satisfaction of a person. one must understand how people judge their life beforehand. As part of the components of SWB, the SWLS is narrowly focused to assess global life satisfaction of a person. Like LAP instrument, we assume SWLS can be utilized for various practical applications on different life situations: the consumption choice between genuine or counterfeit luxury brands. Furnham and Valgeirsson (2007) studied the effect of life values and materialism of consumers on buying counterfeit products. The study examined attitudes, beliefs, and personality traits that influence in consumer's willingness to buy counterfeit products. Findings such as married couples are more likely to purchase counterfeits and people with no religious background being more likely to purchase counterfeits are some of the results replicable in our study. Vida(2007) found out that more religious people are more concerned by the embarrassment potential of being discovered than less religious people, thereby they tend to avoid counterfeit consumption. Through examining these findings, following hypotheses are formed.

H8: Compared to non-users, the genuine luxury brand users are highly likely served by such life attitudes as high degree of life purpose, life control, will to meaning. goal seeking, future meaning to fulfil, life satisfaction, and religiosity.

H9: Compared to non-users, the counterfeit luxury brand users are highly likely served by such life attitudes as low degree of life purpose, will to meaning. goal seeking, future meaning to fulfil, life satisfaction, religiosity, and high degree of life control.

Life control is defined as "freedom to make 
all life choices." We believe those who have good internal control makes logical decisionmakings in shopping goods as well, not be swept away by fashion trend nor colleague pressure. These people are assume to have tendency to consume products based on their own will, and what they believe as logical choice for them regardless of its brand names or origin. Frankly, we believe these people have tendency to belong in both-product consumption group. We presumed both-users have dispositions of fun-loving and enjoyment of diverse life experiences. Their life attitude is more flexible than those insist on one type product consumption. We postulate following hypothesis.
H10: Compared to non-users, the both-users are highly likely served by such life attitudes as high degree of life control.

The moderated effects of age, gender, marital status, income, and age gap between couples on LAP(life attitude profile), SWLS(satisfaction with life scale), and religiosity are also considered.

H11a: Compared to non-users, the genuine luxury brand users are highly likely to be served by the moderating effects of such socio-psychological indicators as high in age, female gender, singles in marital status, high income, and high

〈Figure 1〉 Conceptual Model

\section{functional theories of attitude}

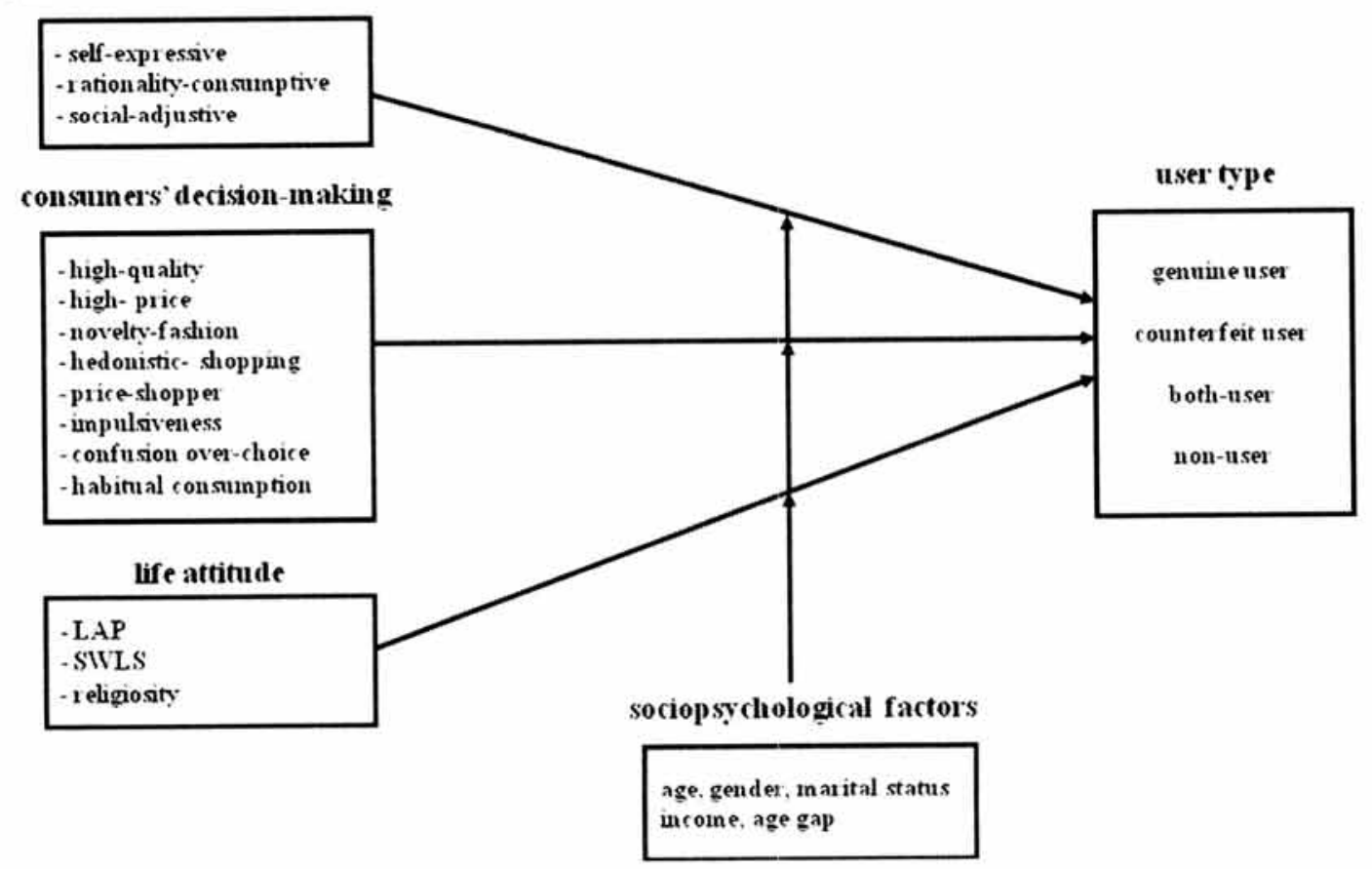

82 ASIA MARKETING JOURNAL Vol. 14 No. 03 October 2012 
age gap between couples, on the causal relationships between LAP(existential vacuum exempted as explained). SWLS (satisfaction with life scale), and religiosity to different user types of luxury brands.

H11b: Compared to non-users, the counterfeit luxury brand users are highly likely to be served by the moderating effects of such socio-psychological indicators as low in age, male gender, married in marital status, low income, and low age gap between couples, on the causal relationships between LAP(existential vacuum exempted as explained), SWLS (satisfaction with life scale), and religiosity to different user types of luxury brands.

\section{Methodology}

\subsection{Instrument Development}

For measures of self-expressive, rationalityconsumptive, and social-adjustive functions we conducted focus group interview to develop new measures, modify and give retouch on existing measures utilized in the study of Wilcox (2009) which have been validated from the prior research. Two rounds of focus group interviews were conducted: first on eight participants: including two males and six females all college students: ages in their 20s and 30s who had prior exposures to both genuine luxury brands and counterfeit luxury brands: mostly with bags and wallets: One male participant belonged in the category of non-user. This gave us a chance to listen and learn from the non-user's perspective of luxury brands. In second round of focus group interview, we had another group of participants, all female student ages in their 20s who had prior experiences to both genuine luxury brands and counterfeit luxury brands joined the study. They all had pretty fair knowledge of non-deceptive counterfeits. During the process of instrument development, a vast collection of items was viewed and developed for the purpose of questionnaire constitution based not only on conceptual aspects, but more on practical, and real-life situations, ensuring that these items connects the construct's domain. In this process, focus group interviewees are asked to decide target luxury products of the study. Regardless of gender bags, wallets, and watches are most widely consumed luxury brands which is quite coherent with the numbers from Korea Customs Service as previously stated, thereby selected. Following this stage, two scholars having high experience in survey research and expertise in the subject domain were asked to assess the instrument. Based on the feedback from the experts, some questions were rephrased for improvement, and of their clarity. As a result, items in the questionnaire were revised 
before they were distributed for data collection. Each item is measured using a seven-point Likert scale.

Based on the original four items of selfexpressive(or value expressive) measure(i.e. reflection of self, self-identity, self-expression, and self-definition) and four items of socialadjustive measure(i.e. social status, social situation, observation by others, and an envious look from others), total of $\operatorname{six}(6)$ items of selfexpressive attitude(i.e. self-reflection, individuality, self-fit, self-definition, self-expression, and selfrealization), six(6) items of rationality-consumptive attitude(i.e. quality, preliminary test, curiosity. variety of design and specification, financial reason, and practicality) and four(4) items of social-adjustive attitude (i.e. social situation. social status, adjusting to social group, and better treatment form others) were selected, reviewed, and finalized. For measures of decision-making styles on consumers product consumption, we adopted, yet modified to fit for the study purpose, existing scales validated by Sproles and Kendall(1986). The instrument composed of eight independently significant decision-making styles in consumers' product consumption: four (4) items of high-quality(i.e. high expectation. perfect or best to me, perfectionism in shopping, and best overall), high-price(this measure is newly developed which is composed of selfdeveloped five(5) items: top brand names, known as top class, expensive items in store, prefer to top-notch items, and high price yields to high quality), three(3) items of noveltyfashion(i.e. latest trend, variety-seeking, new and interesting items), four(4) items of hedonistic shopping(i.e. pleasurable activity, waste of time(-), for fun, and enjoy shopping itself), two(2) items of price-shopping(i.e. wait for sales period, and preference on cheaper priced items), three(3) items of impulsiveness(i.e. spendings are carefully planned and monitored, postpurchase dissonance, and plan ahead before shopping), three(3) items of confusion from over-choice(i.e. too many choices makes me confused, difficult to decide where to shop, and hard to pick from finalized ones), and finally two(2) items of habitual consumption(i.e. tend to visit same stores over and over, repetitive consumption on the same brand) were selected. reviewed, and finalized. Lastly, for life attitude measurement, LAP(Reker and Peacock 1981). SWLS(Diener et al. 1985), and religiosity (DDB Life Style Survey 2000) are adopted. Total of three(3) items of life purpose(i.e. meaningfulness of life, feelings of fulfillment, and set life objective), four(4) items of life control(i.e. life I pursue, self-control, self-achievement, the way planned, and decide things on my own), three (3) items of death acceptance(i.e. natural part of life, not worried about death), two(2) items of will to mean(i.e. ultimate meaning of life, and accountable for life), two(2) items of goal seeking(i.e. achieve new goals in the future, and advance to 'new worlds'), three(3) items of future meaning to fulfill(i.e. better future, 
new goal after another, and best is not yet to come), three(3) items of satisfaction with life style(i.e. quite satisfied with personal life, with to have different lifestyle(-), and complaints(-)), and finally two(2) items of religiosity(i.e. have specific religion, and believe in God) were selected, reviewed, and finalized(the minus sign in the parentheses indicate items are negatively stated which should be scored by reversing the scale in the analyses).

\subsection{Sample and Data Collection}

The data were collected through off-line survey. Sample population constitutes ages between 20 s to 50 s who had prior exposure to consumption of luxury products regardless of authenticity. Total of 450 questionnaires were distributed and 430 valid ones are obtained. The demographic characteristic on study participants shows following composition: males 114(26.5\%). females $316(73.5 \%)$, married 50(11.6\%), single $380(88.4 \%)$, ages between $20-29$ is $344(79.9 \%)$. between $30-39$ is $52(12.2 \%)$, between $40-49$ is $16(3.7 \%)$, and 50 and over is $18(4.2 \%)$. In terms of education, high school graduates are $9(2.1 \%)$, some college is $229(53.3 \%)$, college graduate is $114(26.5 \%)$, some graduate is 49 (11.4\%), and graduated grad school is $29(6.7 \%)$. For income levels, monthly earning 2 million won and below is $89(20.7 \%), 2-4$ million is 162 (37.7\%), 4-6 million is $102(23.7 \%), 6-8$ million is $41(9.5 \%)$, and 8 million over is $36(8.4 \%)$.
The personal luxury possessions are limited to bags, watches, and purses due to these three items are most frequently purchased and getting most wide attentions from the public. We did not include clothing which is third largest imports according to Korea Customs Service due to hard remembrance of people on the items they bought. In another words, from the findings of our pilot test, our participants had trouble remembering number of items and brand names on their personal belongings of clothing, while on bags, watches, and purses they showed clear recollection. The questionnaire also contained open-ended questions regarding type of luxury brands participants consume. Some of the brand names showed are listed below in the order of response rate: Louis Vuitton(19.4\%), Gucci (13.9\%). Chanel(8.8\%). Prada $(7.0 \%)$, Coach $(5.0 \%)$, Ferragamo(5.0\%), Burburrys $(4.1 \%)$. Armani(3.0\%), Louis Quatorze(2.0\%), D\&G (1.6\%), Mark Jacobs(1.4\%), Paul Smith(1.4\%). Christian Dior(1.1\%), and others(such as Fendi, Etro, CK, and Bally).

The different types of luxury brand consumption indicate genuine brand users $(170(39.4 \%))$ scored first, followed by both-users(135(31.4\%)), non-users $(102(23.7 \%))$, and counterfeit users $(24(56 \%))$. In the questionnaire, study participants were asked such question items as: total number of luxury possessions and what they are, number of items received from significant other, number of items received from close friends or relatives, and number of items self 
purchased, to understand sources of possessions. For the case of genuine products, average number of personal possessions is about 6 to 7 . Of these, self-purchase was about $54 \%$, received from significant other was roughly $34 \%$, and rest for $12 \%$ of portion. For the case of counterfeit products, average number of personal possessions is about 9 to 10 . Of these, selfpurchase was about $52 \%$, received from significant other was roughly $32 \%$, and rest for $16 \%$ of portion. Our original assumption on luxury products being exchanged between couples accounts for significant portion of personal luxury possessions fall short for the expectation. The self-purchase took more than half of total personal possessions. However, more than $80 \%$ of personal luxury possessions came from either self or significant other, the effect of age gap on main effect is continued to proceed.

\section{Analyses and Results}

\subsection{Test for Moderating Effect}

To test moderated effects of age, gender, marital status, income, and age gap between couples in our study model, we conducted Chi-square test to see if groups on these construct are significantly different. For gender, we have more females(316) than male(114) participants. Gender across different user types: genuine user, coun- terfeit user, both-user and non-user, we have Chi-square value of $16.539(\mathrm{df}=3 . \mathrm{p}=0.001)$ which makes it statistically significant. For marital status, we have more singles(380) compared to married ones(50). Again, marital status across different user types, we have $\mathrm{Chi}$-square value of $23.942(\mathrm{df}=3, \mathrm{p}=0.000)$. To assess income effect, we divided our sample population into three different income groups: high(monthly earnings more than 5 million won), medium (monthly earnings between 2 million to 5 million won), and low(monthly earnings below 2 million won) groups. There are no definite criteria for classification of income groups as such. However, we followed the ideas from the pilot test. And fortunately, about one third of our sample population belongs to each group we classified. The result indicated significant group difference exists across different user types with Chi-square value of $16.078(d f=6, p=0.013)$. To assess age effect, study participants were divided into three age groups: 20s(344), 30s(52), and over 40 s(16). The result indicated significant group difference exists across different user types with Chi-square value of $31.810(\mathrm{df}=6, \mathrm{p}=0.000)$. Lastly for age gap between couples, study participants were divided into three age gap groups: same age (228), 1 to 4 years of difference(160). and over 5 years of difference(41). Again, we followed ideas from the pilot test to understand what normally considered as high and low age gap between couples by our study participants. Interestingly enough, most people were thinking 
up to four years of age gap is acceptable while over five years is beginning to think little too much. The result indicated significant group difference exists across different user types with Chi-square value of $28.387(\mathrm{df}=6, \mathrm{p}=0.000)$. Therefore, different groups in age, gender, marital status, income, and age gap between couples are validated to put to use for moderated effects in further analyses.

\subsection{Factor Analysis}

To understand underlying structure of construct, principal component factor analysis with varimax rotation is conducted. To see if preconditions to conduct factor analysis, KMO and Bartlett's test of sphericity and measures of sampling adequacy are conducted before conducting factor analyses to see if preconditions meet). The priori constraints on the estimation of components were left to open. The rationale for this is to see whether our newly introduced conceptual domain of rationality-consumptive function stands. The criteria for extraction were set at eigen values of 1.0 or higher, and factor loadings for over 0.5 . For motivations for luxury brands consumption: self-expressive, rationalityconsumptive, and social-adjustive functions. Total of 16 -items resulted with three factor solutions without any eliminated items. Cronbach's Alpha coefficients were calculated for each factor scale to assess internal consistency which ranges from 0.83 (rationality-consumptive attitude) to 0.90 (social adjustment attitude) with self-expressive function scored in between the two(0.84).

A scree plot revealed a flattening of the curve for all factors above the first three. Therefore three-factor solution conservatively appears to be interpretable. accounting for $61.4 \%$ of the total variance. The data for decision-making styles on consumers product consumption were also subjected to factor analysis with varimax rotation. Although, we employed eight previously validated scales from Sproles and Kendall(1986) with touch of slight modification to make sure items in study tapped the construct's domain, the priori constraints on the estimation of components was left to open as well. Total of 16items with five(5) factor solution resulted: highquality (2-items), high-price(5-items), hedonic consumption(4-items), impulsiveness(3-items). and habitual consumption(2-items). The noveltyfashion consciousness, price-shopping consciousness, and confusion from over-choice are dropped. Cronbach's Alpha coefficients were calculated for each factor finalized to assess internal consistency: high-quality(0.6), high-price(0.68), hedonistic shopping (0.78), impulsiveness (0.70), and habitual consumption(0.78). The coefficients calculated here for each factor is comparatively lower than that of attitudes. However, all values are well within the range of 0.5 (Hair $\mathrm{Jr}$. et al. 2010) or 0.6 (Tabachnick and Fidell 1996). The five-factor solution explained $62.3 \%$ of the total variance. The data for life attitude measures on individuals are subjected to factor analysis 
$\langle$ Table 1〉 Theories of Attitude

\begin{tabular}{|c|c|c|c|c|}
\hline \multicolumn{2}{|r|}{ Items } & Factor 1 & Factor 2 & Factor 3 \\
\hline S-El & Self-reflection & .792 & .095 & .080 \\
\hline S-E2 & Individuality & .791 & .086 & -.032 \\
\hline S-E3 & Self-fit & .710 & -.074 & .174 \\
\hline S-E4 & Self-definition & .700 & .018 & .200 \\
\hline S-E6 & Self-realization & .689 & .074 & 290 \\
\hline S-E5 & Self-expression & .667 & .142 & .166 \\
\hline $\mathrm{R}-\mathrm{C} 2$ & Preliminary test & .115 & .759 & .145 \\
\hline $\mathrm{R}-\mathrm{CA}$ & Variety of colors and designs & -.014 & .743 & .183 \\
\hline $\mathrm{R}-\mathrm{C} 3$ & Curiosity & .168 & .702 & .147 \\
\hline $\mathrm{R}-\mathrm{C} 6$ & Practicality & -.063 & .671 & .400 \\
\hline $\mathrm{R}-\mathrm{Cl}$ & Good quality & -.020 & .656 & .310 \\
\hline $\mathrm{R}-\mathrm{C} 5$ & Financial reason & .242 & .517 & .466 \\
\hline S-A2 & Social status & .244 & .328 & .829 \\
\hline $\mathrm{S}-\mathrm{A} 3$ & Adjusting to social group & 206 & .221 & .810 \\
\hline S-Al & Social situation & .210 & .384 & .762 \\
\hline S-A4 & Better treatment from others & .200 & .298 & .707 \\
\hline & Factor Name & Self- Expressive) & $\begin{array}{l}\text { Rationality- } \\
\text { Consumptive }\end{array}$ & Social- Adjustive \\
\hline & Eigen Value & 3.456 & 3.209 & 3.163 \\
\hline & Variance Explained (\%) & 21.599 & 20.057 & 19.766 \\
\hline
\end{tabular}

with varimax rotation. The scales here adopted LAP(Reker and Peacock 1981). SWLS(Diener et al. 1985), and religiosity(DDB Life Style Survey 2000). Total of 13-items with five(5) factor solution resulted: life purpose(3-items), life control(3-items), satisfaction with life(3-items), religiosity(2-items), and death acceptance(2-items). The future meaning to fulfil, goal seeking, and will to mean are dropped. Cronbach's Alpha coefficients were calculated for each factor finalized to assess internal consistency: life purpose (0.85), life control(0.78), satisfaction with life (0.74), religiosity $(0.79)$, and death acceptance (0.67). The five-factor solution explained $74 \%$ of total variance.

Next, all measures above were conducted with confirmatory analyses in an effort to ensure to validate of scales for the newly developed measure. Since many of the measurement items are either revised or modified, and even newly developed to fit for the practical purpose of the study, the exploratory technique conducted above has limited control over which variables are indicators of which latent construct. Employing confirmatory factor analyses in SEM(structural equation modeling) can resolve this problem by ensuring complete control over the specification of indicators for each construct. The results are 
〈Table 2〉 Consumers' Decision-making Styles

\begin{tabular}{c|l|r|r|r|r|r}
\hline \multicolumn{1}{|c|}{ Items } & Factor1 & Facor2 & Factor3 & Factor4 & Factor5 \\
\hline He3 & F For fun & .826 & .027 & .062 & -.002 & .047 \\
\hline He2(-) & Waste of time & .812 & -.125 & -.084 & -.026 & .013 \\
\hline He1 & Pleasurable activity & .776 & .021 & .145 & .098 & .256 \\
\hline He4 & Enjoy shopping itself & .627 & .226 & -.021 & .140 & .069 \\
\hline H-P5 & High price yields to high quality & .007 & .757 & .138 & .059 & -.032 \\
\hline H-P4 & Prefer to top-notch items & .009 & .736 & .077 & .149 & .091 \\
\hline H-P1 & Top brand names. & -.098 & .644 & .032 & -.009 & -.144 \\
\hline H-P3 & Expensive items in store & .266 & .542 & .106 & -.051 & .197 \\
\hline H-P2 & Known as top class & .109 & .493 & .217 & .148 & .307 \\
\hline I2 & Post-purchase dissonance & .093 & .154 & .830 & .095 & -.049 \\
\hline I3(-) & Plan ahead before shopping & .051 & .100 & .787 & -.036 & .147 \\
\hline I1 & Purchase without deep thoughts & -.100 & .164 & .689 & .073 & -.336 \\
\hline H-C2 & Same store & .012 & .054 & .094 & .891 & .106 \\
\hline H-C1 & Same brands & .138 & .129 & .008 & .875 & .116 \\
\hline H-Q3 & High expectation & .127 & .110 & .036 & .128 & .789 \\
\hline H-Q1 & Perfectionism in shopping & .113 & -.003 & -.153 & .086 & .784 \\
\hline & $\quad$ Factor Name & Hedonistic & High- & Impul- & Habitual & High- \\
& Erigen Value & siveness & Consumption & quality \\
\hline
\end{tabular}

〈Table 3〉 Life Attitudes

\begin{tabular}{|c|c|c|c|c|c|c|}
\hline \multicolumn{2}{|r|}{ Items } & \multirow{2}{*}{$\begin{array}{c}\text { Factor1 } \\
.864\end{array}$} & \multirow{2}{*}{$\begin{array}{c}\text { Factor2 } \\
.164\end{array}$} & \multirow{2}{*}{$\begin{array}{c}\text { Factor3 } \\
.160\end{array}$} & \multirow{2}{*}{$\begin{array}{c}\text { Factor4 } \\
.036\end{array}$} & \multirow{2}{*}{$\begin{array}{c}\text { Factor5 } \\
.094\end{array}$} \\
\hline L-P1 & Meaningfulness of life & & & & & \\
\hline L-P3 & Set life objectives & .819 & .204 & .201 & .082 & .094 \\
\hline $\mathrm{L}-\mathrm{P} 2$ & Feelings of fulfillment & .777 & .129 & .264 & .027 & .086 \\
\hline $\mathrm{Sa} 2(-)$ & Wish to have different lifestyle & .125 & .845 & -.093 & .037 & .027 \\
\hline $\operatorname{Sa} 3(-)$ & Complaints & .179 & .781 & .114 & .048 & .034 \\
\hline Sal & Quite satisfied with my life & .149 & .740 & .151 & .058 & .210 \\
\hline $\mathrm{L}-\mathrm{C} 2$ & Self control & .222 & .851 & .851 & -.009 & .045 \\
\hline $\mathrm{L}-\mathrm{C} 3$ & Self achievement & .170 & .835 & .835 & -.018 & .129 \\
\hline $\mathrm{L}-\mathrm{Cl}$ & Life I pursue & .495 & .159 & .614 & .017 & .055 \\
\hline $\mathrm{R} 2$ & Believe in God & .041 & .040 & -.007 & .906 & -.063 \\
\hline R1 & Have specific religion & .062 & .078 & -.009 & .905 & .010 \\
\hline D-Al & Natural part of life & -.032 & .192 & .119 & -.024 & .865 \\
\hline D-A2 & Not worried about death & .269 & .030 & .062 & -.034 & .829 \\
\hline & Factor Name & $\begin{array}{l}\text { Life } \\
\text { purpose }\end{array}$ & Satisfaction & $\begin{array}{l}\text { Life } \\
\text { control }\end{array}$ & Religiosity & $\begin{array}{c}\text { Death } \\
\text { acceptance }\end{array}$ \\
\hline & Eigen Value & 2.494 & 2,033 & 1.997 & 1.658 & 1.532 \\
\hline & Variance Explained $(\%)$ & 19.185 & 15.639 & 15.364 & 12.753 & 11.784 \\
\hline
\end{tabular}


$\langle$ Table 4$\rangle$ CFA on Theories of Attitude

\begin{tabular}{|c|c|c|c|c|}
\hline Construct & Items & $\begin{array}{l}\text { Standardized } \\
\text { loading }\end{array}$ & $\begin{array}{l}\text { Composite } \\
\text { reliability }\end{array}$ & AVE \\
\hline S-E1 & Self-reflection & 0.791 & \multirow{6}{*}{0.888} & \multirow{6}{*}{0.569} \\
\hline S-E2 & Individuality & 0.733 & & \\
\hline S-E3 & Self-fit & 0.710 & & \\
\hline S-E4 & Self-definition & 0.727 & & \\
\hline S-E5 & Self-expression & 0.745 & & \\
\hline S-E6 & Self-realization & 0.814 & & \\
\hline $\mathrm{R}-\mathrm{Cl}$ & Good quality & 0.770 & \multirow{6}{*}{0.898} & \multirow{6}{*}{0.596} \\
\hline $\mathrm{R}-\mathrm{C} 2$ & Preliminary test & 0.751 & & \\
\hline $\mathrm{R}-\mathrm{C} 3$ & Curiosity & 0.709 & & \\
\hline $\mathrm{R}-\mathrm{CA}$ & Variety of colors and designs & 0.766 & & \\
\hline $\mathrm{R}-\mathrm{C} 5$ & Financial reason & 0.789 & & \\
\hline $\mathrm{R}-\mathrm{C} 6$ & Practicality & 0.842 & & \\
\hline S-Al & Social situation & 0.849 & \multirow{4}{*}{0.901} & \multirow{4}{*}{0.696} \\
\hline S-A2 & Social status & 0.934 & & \\
\hline S-A3 & Adjusting to social group & 0.806 & & \\
\hline S-A4 & Better treatment from others & 0.736 & & \\
\hline
\end{tabular}

Chi-square $=278.239, \mathrm{df}=98, \mathrm{p}=0.000, \mathrm{GFI}=0.926, \mathrm{AGFI}=0.898, \mathrm{CFI}=0.946, \mathrm{RMSEA}=0.065$

〈Table 5〉 CFA on Consumers' Decision-making Styles

\begin{tabular}{|c|c|c|c|c|}
\hline Construct & Items & $\begin{array}{c}\text { Standardized } \\
\text { loading }\end{array}$ & $\begin{array}{l}\text { Composite } \\
\text { reliability }\end{array}$ & AVE \\
\hline $\mathrm{H}-\mathrm{Q} 1$ & Perfectionism in shopping & 0.658 & \multirow{2}{*}{0.708} & \multirow{2}{*}{0.551} \\
\hline $\mathrm{H}-\mathrm{Q} 3$ & High expectation & 0.818 & & \\
\hline $\mathrm{H}-\mathrm{P} 1$ & Top brand names. & 0.619 & \multirow{5}{*}{0.864} & \multirow{5}{*}{0.564} \\
\hline $\mathrm{H}-\mathrm{P} 2$ & Known as top class & 0.700 & & \\
\hline $\mathrm{H}-\mathrm{P} 3$ & Expensive items in store & 0.646 & & \\
\hline $\mathrm{H}-\mathrm{P} 4$ & Prefer top-notch items & 0.876 & & \\
\hline $\mathrm{H}-\mathrm{P} 5$ & High price yields to high quality & 0.874 & & \\
\hline $\mathrm{Hel}$ & Pleasurable activity & 0.780 & \multirow{4}{*}{0.821} & \multirow{4}{*}{0.536} \\
\hline $\mathrm{He} 2(-)$ & Waste of time & 0.775 & & \\
\hline $\mathrm{He} 3$ & $\mathrm{~F}$ For fun & 0.742 & & \\
\hline $\mathrm{He} 4$ & Enjoy shopping itself & 0.619 & & \\
\hline I1 & Purchase without deep thoughts & 0.658 & \multirow{3}{*}{0.783} & \multirow{3}{*}{0.550} \\
\hline I2 & Post-purchase dissonance & 0.864 & & \\
\hline $\mathrm{I} 3(-)$ & Plan ahead before shopping & 0.685 & & \\
\hline $\mathrm{H}-\mathrm{Cl}$ & Same brands & 0.904 & \multirow{2}{*}{0.793} & \multirow{2}{*}{0.661} \\
\hline $\mathrm{H}-\mathrm{C} 2$ & Same store & 0.710 & & \\
\hline
\end{tabular}

Chi-square $=242.155, \mathrm{df}=91, \mathrm{p}=0.000, \mathrm{GFI}=0.935, \mathrm{AGFI}=0.903, \mathrm{CFI}=0.910 \mathrm{RMSEA}=0.062$ 
$\langle$ Table 6〉 CFA on Life Attitudes

\begin{tabular}{|c|c|c|c|c|}
\hline Construct & Items & $\begin{array}{l}\text { Standardized } \\
\text { loading }\end{array}$ & $\begin{array}{l}\text { Composite } \\
\text { reliability }\end{array}$ & AVE \\
\hline L-P1 & Meaningfulness of life & 0.850 & \multirow{3}{*}{0.852} & \multirow{3}{*}{0.659} \\
\hline L-P2 & Feelings of fulfillment & 0.742 & & \\
\hline L-P3 & Set life objectives & 0.839 & & \\
\hline $\mathrm{L}-\mathrm{Cl}$ & Life I pursue & 0.865 & \multirow{3}{*}{0.768} & \multirow{3}{*}{0.530} \\
\hline $\mathrm{L}-\mathrm{C} 2$ & Self-control & 0.650 & & \\
\hline $\mathrm{L}-\mathrm{C} 3$ & Self-achievement & 0.647 & & \\
\hline $\mathrm{D}-\mathrm{Al}$ & Natural part of life & 0.969 & \multirow{2}{*}{0.902} & \multirow{2}{*}{0.821} \\
\hline $\mathrm{D}-\mathrm{A} 2$ & Not worried about death & 0.839 & & \\
\hline Sal & Quite satisfied with my life & 0.771 & \multirow{3}{*}{0.808} & \multirow{3}{*}{0.584} \\
\hline $\mathrm{Sa} 2(-)$ & Wish to have different lifestyle & 0.727 & & \\
\hline $\mathrm{Sa} 3(-)$ & Complaints & 0.794 & & \\
\hline R1 & Have specific religion & 0.546 & \multirow{2}{*}{0.722} & \multirow{2}{*}{0.582} \\
\hline $\mathrm{R} 2$ & Believe in God & 0.930 & & \\
\hline
\end{tabular}

Chi-square $=99.723, \mathrm{df}=53, \mathrm{p}=0.000 . \mathrm{GFI}=0.966 . \mathrm{AGFI}=0.942 . \mathrm{CFI}=0.976 . \mathrm{RMSEA}=0.045$

described in following tables.

The results indicated that all standardized loadings are above 0.5 , average variance extracted and composite reliabilities are greater than 0.5 and 0.7 respectively, which are well within the ranges of guidelines offered by Hair et al.(2010). The model fit was good, all within the recommended figures(Hair et al. 2010).

\subsection{Hypotheses Testing}

A scree plot revealed a flattening of the curve for all factors above the first three. Therefore three-factor solution conservatively appears to be interpretable, accounting for $61.4 \%$ of the total variance. The data for decisionmaking styles on consumers' product consumption were also subjected to factor analysis with varimax rotation. Although, we employed eight previously validated scales from Sproles and Kendall(1986) with touch of life attitudes) instead of multiple regression analyses, either discriminant analysis or logit analysis is appropriate. Discriminant analysis is capable of handling two or more groups of dependent variables, where as logit analysis is basically limited in its form to two groups. However, logit analysis can handle more than two groups and is capable of combing with other multivariate techniques such as factor analysis and path analysis (Hair Jr. et al. 2010). Moreover, the method can handle categorical independent variables easily, especially in generating dummy variables (socio-psychological factors are dummy coded in our study) whereas in discriminant analysis, dummy variables can often create problems. 
However the results from both analyses are identical in terms of their interpretation. Therefore, the method of logic regression is preferred and more widely used these days over discriminant analysis and can act as more powerful alternative tool to discriminant analysis(Hair Jr. et al. 2010).

To assess overall model fit in relationship between different motivations to different user types, a logistic regression analysis is estimated based on 430 observations. The log likelihood value (-2LL) is 940.716 , with Chi-square value of 82.730 ( $\mathrm{df}=9, \mathrm{p}=0.000$ ) which makes it statistically significant. In estimating the likelihood of genuine brand users are motivated with selfexpressive and rationally-consumptive attitudes, only self-expressive attitude $(B=0.439, p=0.000)$ showed significance compared to non-users while rationality-consumptive attitude $(B=-0.064, p=$ $0.666)$, and social-adjustive attitude $(B=-0.154$, $\mathrm{p}=0.308$ ) did not hold (partly supporting H1). For estimation of the relationship between likelihood of counterfeit brand users are motivated with rationality-consumptive and social-adjustive functions, only rationality-consumptive attitude ( $B=0.583, p=0.002)$ showed significance while self-expressive attitude $(B=0.113, p=0.643)$, and social-adjustive attitude $(B=-0.052, p=0.841)$ did not hold(partly supporting H2). For estimation of the relationship between the likelihood of both-users are motivated with rationalityconsumptive and social-adjustive functions, both self-expressive attitude $(B=0.638, p=0.000)$ and rationality-consumptive attitude $(B=0,468, p=$ 0.003 ) are proven to be significant(partly supporting $\mathrm{H} 3$ ). Unlike the results from previous studies and our assumption, social-adjustive attitude is found nowhere to be significant in all three assumptions of relationship between different motivations to different user types. The results are indicated in the following table.

A logistic regression analysis is estimated to assess overall model fit in relationship between decision-making styles to different user types. The log likelihood value(-2LL) is 1017.703, with Chi-square value of $36.970(\mathrm{df}=15, \mathrm{p}=0.000$ ) which makes it statistically significant. In estimating the likelihood of different decision-making styles serve for genuine brand users, only high quality $(B=0.246, p=0.048)$ showed significance compared to non-users, while hedonistic shopping $(B=0.146, p=0.165)$ and high-price $(B=0.155$,

〈Table 7〉 Hypotheses Testing 1 3

\begin{tabular}{c|c|c|c|c|c}
\hline User type & Independent variable & B & SE & P & \\
\hline Genuine brand & Self-expressive & 0.246 & 0.124 & 0.048 & Partly supporting H1 \\
\hline Counterfeit brand & Rationality-consumptive & 0.583 & 0.251 & 0.002 & Partly supporting H2 \\
\hline Both user & Self-expressive & 0.638 & 0.142 & 0.000 & \multirow{2}{*}{ Supporting H3 } \\
\hline Both user & Rationality-consumptive & 0.468 & 0.156 & 0.003 & \\
\hline
\end{tabular}


$\mathrm{p}=0.286$ ) did not show significance as assumed in H4 (partly supporting H4). For estimation of the relationship between different decisionmaking styles serve for counterfeit brand users, high-price $(B=-0.586, p=0.039)$ showed significance but in negative direction compared to non-users. Given the fact that price-shopping (value for money) is removed during factor analysis, the high-price conveys opposite direction yet related shades of meaning, which we believe tapping on the same construct's domain. Therefore, we postulate the result of on $\mathrm{H} 5$ holds significance even if it's in opposite direction (support for H5). For estimation of the relationship between different decision-making styles serve for both-users, hedonistic shopping $(B=$ $0.252, p=0.029)$ and high-price $(B=0.409, p=$ $0.008)$ showed significance, while high-quality $(B=0.126, p=0.344)$ did not show significance, and price-shopping is removed during factor analysis(partly supporting H6). The results are indicated in the following table.

We test moderated influence of the sociopsychological constructs(i.e. age, gender, marital status, income, and age gap) on causal relationship between consumers' decision-making styles and different user types. For age effect, consumers in 20s consume genuine brands for high-quality $(B=0.323 . p=0.017)$ reason. whereas those who are not advocating high-price, consume counterfeits $(B=-0.789, p=0.017)$. Consumers in $20 \mathrm{~s}$ and $30 \mathrm{~s}$ consume both products for high-price $(B=0.361 \mathrm{p}=0.030(20 \mathrm{~s}), \mathrm{B}=1.158$, $\mathrm{p}=0.075(30 \mathrm{~s}))$, and hedonistic consumption $(\mathrm{B}=$ $0.240, p=0.066(20 \mathrm{~s}): \quad B=0.601, p=0.095(30 \mathrm{~s})$ ) reasons. For gender effect, females consume genuine brands due to hedonistic $(B=0.241$, $p$ $=0.078)$, and high-quality $(B=0.269, p=0.076)$. reasons, whereas males who are not advocating high-price, consume counterfeits $(B=-1.126, p=$ 0.041). Both females and males consume both products for high-price $(B=0.438, p=0.018$ (females): $\mathrm{B}=0.721, \mathrm{p}=0.024$ (males)) reason. For marital status effect, singles consume genuine brands for high-quality $(B=0.289, p=0.026)$ reason, and consume counterfeits for anti-highprice $(B=-0.720, p=0.020)$ reason. Singles use both products for hedonistic $(B=-0.300, p=0.016)$ and high-price $(B=0.398, p=0.015)$ consumptions. Married couples consume both products for impulsiveness $(B=0.790, p=0.071)$. For income effect, genuine brand users are compose of

〈Table 8〉 Hypotheses Testing $4 \sim 6$

\begin{tabular}{c|c|c|c|c|c}
\hline User type & Independent & B & SE & P & results \\
\hline Genuine brand & High quality & 0.439 & 0.126 & 0.000 & Partly supporting for H4 \\
\hline Counterfeit brand & High price & -0.586 & 0.284 & 0.039 & Partly supporting for H5 \\
\hline \multirow{2}{*}{ Both user } & Hedonistic shopping & 0.252 & 0.115 & 0.029 & \multirow{2}{*}{ Partly supporting for H6 } \\
\cline { 2 - 5 } & High price & 0.409 & 0.153 & 0.008 & \\
\hline
\end{tabular}


high income group for high-quality $(B=0.886$. $p=0.000)$, middle income group for high-price $(B=0.482, p=0.040)$, and low income group for hedonistic shopping $(B=0.827, p=0.001)$ reasons. For age gap effect, the significance showed only on couples with same and close in age (4 years or less). They consume genuine brands for high-quality $(B=0.248, p=0.056)$ reason, and counterfeits for anti-high-price $(B=-0.544, p=$ 0.056 ) reason, and both products for hedonistic shopping $(\mathrm{B}=-0.267, \mathrm{p}=0.030)$ and high-price ( $B=0.394, p=0.012$ ) reasons (partly supporting H7). The results are indicated in the following table.

Finally, in assessment of the model on life attitude to different user types, the overall model fit was not proven to be significant. The $\log$ likelihood value(-2LL) is 1031.767, with Chi-square value of $13.777(\mathrm{df}=12, \mathrm{p}=0.315$ ). However, we continued our analyses on main effect and moderated influences to see if any noteworthy suggestions are engaged. For main effect, only life control is significantly associated with both users $(B=0.294, p=0.059)$ (not supporting for $\mathrm{H} 8$ and $\mathrm{H} 9$, but supporting $\mathrm{H} 10$ ). We test moderated influence of the sociopsychological constructs on causal relationship between life attitude and different user types. For gender effect, males with negative life satisfaction $(B=-0.717, p=0.092)$ consume coun-

〈Table 9〉 Hypothesis Testing 7

\begin{tabular}{|c|c|c|c|c|c|}
\hline User type & Independent variable & $\mathrm{B}$ & SE & $\mathrm{P}$ & \\
\hline Genuine brand & Hedonistic shopping*female & 0.241 & 0.137 & 0.078 & \multirow{4}{*}{ Partly supporting for $\mathrm{H} 7 \mathrm{a}$} \\
\hline Genuine brand & High quality*female & 0.269 & 0.152 & 0.076 & \\
\hline Genuine brand & High quality*single & 0.289 & 0.129 & 0.026 & \\
\hline Genuine brand & High quality*high income & 0.886 & 0.250 & 0.000 & \\
\hline Counterfeit brand & High price* 4 years or less & -0.544 & 0.285 & 0.056 & \multirow{2}{*}{ Partly supporting for H7b } \\
\hline Counterfeit brand & High price*male & -1.126 & 0.551 & 0.041 & \\
\hline
\end{tabular}

$\langle$ Table 10〉 Hypotheses Testing 8 10

\begin{tabular}{c|c|c|c|c|c}
\hline User type & Independent variable & $\mathrm{B}$ & $\mathrm{SE}$ & $\mathrm{P}$ & \\
\hline Both user & Life control & 0.294 & 0.156 & 0.059 & $\begin{array}{c}\text { Supporting for H10 } \\
\text { (Not supporting for H8, H9) }\end{array}$ \\
\hline
\end{tabular}

〈Table 11〉 Hypothesis Testing 11

\begin{tabular}{c|c|c|c|c|c}
\hline User type & Independent variable & B & SE & P & \\
\hline Counterfeit brand & Life satisfaction*male & -0.717 & 0.426 & 0.092 & \multirow{2}{*}{ Partly supporting H11b } \\
\hline Counterfeit brand & Life satisfaction*low income & -0.649 & 0.394 & 0.099 & \\
\hline
\end{tabular}


terfeits. For marital status effect, singles with significant life control $(B=0.311, p=0.064)$ con- $^{-}$ sume both products, while the married ones with significant life control $(B=0.690, p=0.034)$ consume both products. For income effect, low income group with negative life satisfaction ( $B=-0.649, p=0.099)$ consume counterfeits. The high income group with life control $(B=0.428$. $\mathrm{p}=0.089$ ) consume both products. In terms of age gap effect, the significance showed only on couples with big age gap(5years or more). They consume both products for negative life satisfaction $(B=-1.301, p=0.086)$ and life control ( $B=1.955, p=0.058)$ reasons (partly suggesting connections in H11).

\section{Conclusions and Suggestions}

The analyses of proposed model based on previous research and our theoretical consideration was partly confirmed. In functional theories of attitude, rationality-consumptive attitude is newly introduced and assumed to have critical relationships with both genuine and counterfeit luxury brands consumption. The analyses revealed that only self-expressive function relates to genuine brand consumption whereas, rationalityconsumptive function relates only to counterfeit brand consumption: moreover, these two functions serve both consumption types. Here, the motive for genuine users and that of coun- terfeit users all passed down onto both-users. We assumed that social-adjustive motive influences both counterfeit and both-users. From previous studies social-adjustive function is claimed to have connection with luxury product consumption for individual's urge to gain social approval, and projection of pleasing images in social settings. However this motive was not present neither in genuine nor counterfeit brand consumptions in our study. Presumably, the phenomenon is ascribed to widespread consumption of luxury brands these days. The widespread consumption of luxury brands makes it less special for luxury consumers to portray their image in social settings but nearly just like the common items they have. Regardless of authenticity, luxury brands are seen anywhere and anytime. For instance, hypocoristic name for Louis Vuitton bag is "three-second bag, meaning the bag is observable every three seconds if you walk down the street. Such views are attributable to more availability of distributors for both genuine and counterfeit luxury brands, particularly the latter. Another contributing factor is on the significant improvement of quality of counterfeits(i.e. high resemblance in product form) which makes it more difficult for consumers to distinguish between counterfeits from genuine ones. This in turn, will make consumers to trust and rely on quality of counterfeits, thereby encourages its widespread consumption. At the same time, counterfeit consumption is claimed to build brand awareness 
(Shultz and Saporito 1996) and increase the snob value for genuine brands(Barnett 2005). In such circumstances, the consumption on both genuine and counterfeit brands is subject to increase. As a consequence, the widespread consumption on luxury brands have affected to gradual disappearance of consumers' urge to have social image projection due to their depreciated value caused by deterioration of image, and you don't feel special by having them on you, just as before. Thus, such motive of socialadjustment is sharply diminished.

To further understand the evaporation of socialadjustive function in our analyses, moderating effects of socio-psychological indicators in the relationship are examined. For age effect, consumers in their 30s consume counterfeits for rationality-consumptive reason, while both $20 \mathrm{~s}$ and 30s consume both-products for self-expressive and rationality-consumptive reasons. For gender effect, females consume counterfeits and bothproducts under rationality-consumptive reason. For marital status effect, both singles and married ones consume counterfeits and both-products for rationality-consumptive reason. In addition, singles also consume both-products for selfexpressive reason. For income effect, the medium income group with rationality-consumptive motive consumes counterfeits, while all levels of income groups consume both-products for self-expressive motive. For age gap effect, on couples with same or close in age consume counterfeits for rationality-consumptive reason, whereas all age gap groups consume both-products for self-expressive reason. There is a thread of connection between the results from main relationship and the moderating effects: the rationality-consumptive motive appeared to be significant in all areas of counterfeit consumption. while social-adjustive motive is totally disappeared. Looking at the results of moderating effect, females are the major consumers for both counterfeits and both-products. Not only high income, high age, and high age gap groups do consume genuine brands, but all different levels of income, age, and age gap groups significantly consume genuine products if they have selfexpressive motive. Self-expressive motive acts as most powerful catalyst in consumption of genuine brands. It triggers off genuine brand consumption of consumers even in low income situations people face. We presumed the counterfeit consumption prevails in low age gap group, and this was only true under the condition, if they hold rationality-consumptive motive. Again, the rationality-consumptive motive is also the most powerful catalyst which can trigger low age gap group to consume counterfeits, if not this group is normally oriented on consumption of genuine products.

The self-expressive and social-adjustive attitudes keep with the theory of self construals: individual differences in structure of the self. Here, the independent self-construal indicates the representation of others are separate from the self, while interdependent self-construal 
represents others are considered part of the self(Markus and Kitayama 1991: Cross and Madison 1997). Here, the self-expressive attitude signifies independent self-construal and socialadjustive attitude signifies interdependent selfconstrual. This means consumers with independent self-construal are highly likely to consume genuine brands while consumers with interdependent self-construal are supposedly to consume counterfeits. However, the absence of social-adjustive attitude in the study results indicates interdependent self-construal no longer stands in consumption of counterfeit luxury products. Indeed, the consumption of genuine luxury brands is the reflection of individualistic goals and relationship with others may serve as mirrors for the individual's comparison of self with others. It is a mean to demonstrate uniqueness by an assertion of dominance of others (Cross and Madison 1997). On the other hand, counterfeit consumptions should not be considered in light of thoughts, feelings, and behaviors of close others. The responsiveness to the needs of others does not shape individual decisions on counterfeit consumption.

On relationship between consumers decisionmaking styles to different consumption types, we found high-quality is the major motivating behavior for genuine brand consumption, while high-price sublation is tied for counterfeit consumption. Both hedonistic and high-price aspiration is strongly tied to both-product consumption. Unlike the results shown in rela- tionships on functional theories and different user types, which the properties of genuine and counterfeit consumption each, are additively passed down onto both-product consumption, the disposition for both-users here, showed totally different decision-making styles compared to other two groups. The moderated effects of sociopsychological factors indicated that along with high-quality behavior which is the primary indicator for genuine brand consumption, hedonistic shopping behavior also showed support for female consumers on genuine brand consumption. Singles consume both-products for hedonistic and highprice aspiration behaviors, while married couples consume both-products for impulsiveness. View from the studies of Furnham and Valgeirsson (2007), in which married couples are more likely to purchase counterfeits, we presume consumers in married state may have consumed genuine brands when they were in single state, like the singles we found in our study, but after marriage perhaps they turned their shopping taste to counterfeits due to other important matters in life. Between income levels and user types. groups in all income levels showed significance in genuine brands consumption for different reasons: low income group for hedonistic behavior, medium income group for high-price aspiration behavior, and high income group for high-quality behavior. Counterfeits are consumed by high income group if they support for highprice sublation. In addition. counterfeits consumption is significant if consumers(i.e. low 
age group and low age gap group) support for high-price sublation. Consequently, high-price sublation is found to be most powerful indicator for anticipating consumers' counterfeit consumption, even more powerful predictor than income levels in our study. Findings indicate that our original assumptions of "low in age, and low age gap between couples are positively related to counterfeit brand consumption" are not supported, rather these groups more likely to consume genuine brands. This corresponds with the results of descriptive statistics on cross tabulation for genuine and counterfeit possessions on single and married couples with marital status applied. The results well indicated that for married couples, small age gap groups(same age $(50 \%)$, under $5(55 \%))$ consume genuine brands, whereas big age gap couples(47.8\%) consume both-products. Also for singles, all age gap groups significantly consume genuine brands.

On relationship between life attitudes to different user types, the significance of model fit was not validated. Contrary to our expectations, only life control out of five life attitudes survived from factor analyses impacted on relationship: life control is a good indicator for both-product consumption. Unlike findings of Vida(2007), religiosity in our study did not support for counterfeit consumption, instead it's disappeared in the relationship. Taking into consideration of socio-psychological indicators in the relationship, life control is still strongly expressed showing significance in most areas of socio-psychological indicators: Singles, high income earners, people their 20s, and high age gap between couples with high life control consume both-products. At the same time, low life satisfaction appears to show significance in counterfeit consumption: males with low life satisfaction, and low income group with low life satisfaction. Life control reflects as flexibility of life attitudes which in turn, does not anchor consumers to stick to only on one type product consumption. It's a good predictor for bothproduct consumption. On the other hand, life satisfaction sticks to counterfeit consumption only. Those less satisfied consumers tend to consume counterfeits.

Limitation of the study lies in the number of sample population on exclusive genuine brand users and counterfeit brand users. In fact, most people belong to both-product consumption group. The implication of the study is in expansion of existing frameworks to identify relative importance of each predictor and provision of consumer profiles on their preferences on different consumption choices. Marketers need to develop separate strategies utilizing self-expressive attitude, rationality-consumptive attitude, high-price sublation, and life control which found to be highly significant agents to strongly influence consumers' consumption choice. The strategies must be developed in message framing where self-expressive message scheme is adopted for genuine brands while, rationality-consumptive message scheme is employed for counterfeits 
(for those on-line businesses where they exclusively offer for counterfeits). In addition, young singles although they may not be considered as economically stable group, yet powerful consumers for genuine brands consumption. Meanwhile. married ones can be instigated for consumption of genuine brands through having them to predispose recollecting good old early days.

〈Recieved August 23. 2012〉

〈Revised September 30. 2012〉

〈Accepted October 7, 2012〉

\section{References}

Albers-Miller, Nancy D. (1999), "Consumer Misbehavior: Why People Buy Illicit Goods," Journal of Consumer Marketing, 16 (3), 273-87.

Al-Khatib, Jamal A., Christopher J. Robertson. and Dana-Nicoleta Lascu (2004). "Postcommunist consumer ethics: The case of Romania," Journal of Business Ethics, 54 (1), 81-95.

Barnett, Jonathan M. (2005), "Shopping for Gucci on Canal Street: Reflections on Status Consumption, Intellectual Property, and the Incentive Thesis," Virginia Law Review, 91, 1381-1423.

Bettman, James R. (1979), An Information Processing Theory of Consumer Choice, Reading. Massachusetts: Addison Wesley Pu- blishing Company.

Bloch. Peter H., Ronald F. Bush, and Leland Campbell (1993), "Consumer 'Accomplices' in Product Counterfeiting." Journal of Consumer Marketing. 10 (4), 27-36.

Bushman. Brad J. (1993). "What's in a name? The moderating role of public self-consciousness on the relation between brand label and brand preference," Journal of Applied Psychology, 78 (5), 857-61.

Chakraborty, Goutam, Anthony Allred, Ajay Siningh Sukhdial, and Terry Bristol (1997), "Use of Negative Cues to Reduce Demand for Counterfeit Products," Advances in Consumer Research, 24, 345-49.

Cross Susan E. and Laura Madison (1997). "Models of the Self: Self-Construals and Gender," Psychological Bulletine, 122(1), 5-37,

DDB Lifestyle Survey (2000). Worldwide Communications Group Inc.

DeBono. Kenneth G. (1987), "Investigating the Social Adjustive and Value Expressive Functions of Attitudes: Implications for Persuasion Precesses," Journal of Personality and Social Psychology, 52 (2), 279-87.

Diener, Ed (1984), "Subjective well-being," Psychological Bulletin. 95 (3), 542-75. , Robert A. Emmons, Randy J. Larsen. and Sharon Griffin (1985), "The Satisfaction With Life Scale," Journal of Personality Assessment, 49 (1), 71-75.

Dubinsky, Alan J., Ragan Nataraajan, and 
Wen-Yeh Huang (2005), "Consumer's moral philosophies: Identifying the idealist and the relativist," Journal of Business Research, 58 (12), 1690-1701.

Dubois, Bernard and Patrick Duquesne (1993). "The market for luxury goods: income versus culture," European Journal of Marketing. 27 (1), 35-44. and Claire Paternault (1995), "Observations: understanding the world of international luxury brands: the dream formula," Journal of Advertising Research. 35 (4), 69-75.

Ferrell, O. C. and Larry G. Gresham (1985), "A contingency framework for understanding ethical decision making in marketing," Journal of Marketing, 49 (3), 87-96.

Furnham, Adrian and Halldor Valgeirsson (2007),

"The effect of life values and materialism on buying counterfeit products," The Journal of Socio-Economics, 36 (5), 677-85.

Gentry, James W., Sanjay Putrevu, and Clifford Schultz (2006), "The effects of Counterfeiting on Consumer Search," Journal of Consumer Behavior, 5 (3), 245-56.

Grossman, Gene M., and Carl Shapiro (1988). "Counterfeit-product trade," The American Economic Review, 78 (1), 59-75.

Hair, Joseph F. Jr., William C. Black, Barry J. Babin, and Rolph E. Anderson (2010), Multivariate Data Analysis, 7th Edition, Prentice-Hall International.

Herald News (2011), http://news.heraldm,com/ view.php?ud $=20111208000079 \& \mathrm{md}=201$ $11208000079 \& \mathrm{md}=20111208084918 \_9$.

Hoe, Lee, Gillian Hogg, and Susan Hart (2003). "Faking it: Counterfeiting and consumer contradictions," European Advances in Consumer Research, 6, 60-67.

Jacoby, Jacob and Robert W. Chestnut (1978), Brand Loyalty: Measurement and Management, New York: John Wiley and Sons,

Katz, Daniel (1960), “The Functional Approach to the Study of Attitudes," Public Opinion Quarterly, 24 (2), 163-204.

Kim, Joo-Ho (2011), "The Influence of Chinese Interpersonal Culture on Counterfeit Brand," Journal of Korean Marketing Association, 13(2), 27-48.

Lai, Kay Ka-Yuk and Judith Lynne Zaichkowsky (1999), "Brand Imitation: Do the Chinese Have Different Views?." Asia Pacific Journal of Management, 16 (2), 175-92.

Lee, Dongdae (2004), "Effects of Quality and Price of Counterfeits on Evaluation of Counterfeit and Genuine Fashion Luxury Brands," Journal of Korean Marketing Association, 19(1), 97-129.

Markus, H. R. and S. Kitayama (1991), " $\mathrm{Cu}$ Iture and the self: Implications for cognition, emotion, and motivation," Psychological Review, 98, 224-253.

Maynes, E. Scott (1976), Decision-Making for Consumers: An Introduction to Consumer Economics, New York: Macmillan. Miller, Roger LeRoy (1981), Economic Issues 
for Consumers, Third Edition, New York:

West Publishing Company.

Nia, Arghavan and Judith Lynne Zaichkowsky (2000), "Do counterfeits devalue the ownership of luxury brands," Journal of Product \& Brand Management. 9 (7), 485-97. Parloff, R. (2006). "Not Exactly Counterfeit," Fortune, 153 (8), 108-12.

Penz. Elfriede and Barbara Stottinger (2005), "Forget the 'Real" Thing: Take the Copy! An Explanatory Model for the Volitional Purchase of Counterfeit Products," Advances in Consumer Research, 32 (1), 568-75.

Phau, Ian, Min Teah, and Agnes Lee (2009). "Targeting Buyers of Counterfeits of $\mathrm{Lu}^{-}$ xury Brands: A Study of Attitudes of Singaporean Consumers," Journal of Targeting. Measurement and Analysis of Marketing, 17 (1), 3-15.

Phillips, Tim (2005), Knockoff: The Deadly Trade in Counterfeit Goods, Sterling, VA: Kogan Page.

Reker, Gary T. and Edward. J. Peacock (1981). "The Life Attitude Profile(LAP): A multidimensional instrument for assessing attitudes toward life," Canadian Journal of Behavioural Science/Revue canadienne des Sciences du comportement, 13 (3), 264-73. Shavitt, Sharon (1989). "Products, Personalities and Situations in Attitude Functions: Implications for Consumer Behavior," Advances in Consumer Research, 16 (1), 300-05.

Shin, D. C. and D. M. Johnson (1978). "Avowed happiness as an overall assessment of the quality of life," Social Indicators Research, 5 (1-4), 475-92.

Shultz, Clifford J. and Bill Saporito (1996). "Protecting Intellectual Property: Strategies and Recommendations to Deter Counterfeiting and Brand Piracy in International Markets," Columbia Journal of World Business, 31 (1), 18-28.

Simpson, Penny M.. Debasish Banerjee, and Claude L. Simpson (1994), "Softlifting: A model of motivating factors," Journal of Business Ethics, 13 (6), 431-38.

Smith, Brewster M., Jerome S. Bruner, and Robert W. White (1956), Opinions and Personality, New York: John Wiley \& Sons. Snyder, Mark and Kenneth G. DeBono (1985). "Appeals to Image and Claims About Quality: Understanding the Psychology of Advertising," Journal of Personality and Social Psychology, 49 (3), 586-97.

Sproles, George B. (1979), Fashion: Consumer Behavior Toward Dress, Minneapolis: Burgess Publishing Company. and Elizabeth L. Kendall (1986), "A Methodology for Profiling Consumers' Decision-Making Styles," Journal of Consumer Affairs, 20 (2), 267-79.

Stipp, D. (1996), "Farewell my logo," Fortune, 27 (May), 128-40.

Stoettinger, Barbara and Elfriede Penz (2003), "The demand for counterfeits: Are consumers across borders triggered by same 
motives?." Akademija MM. 10, 81-89.

Tabachnick, Barbara G. and Linda S. Fidell (1996), Using Multivariate Statistics, Third Edition, New York: Hamper College Publishers.

Thorelli, Hans B., Helmut Becker, and Jack Engeldow (1975), The Information Seekers, Cambridge, Massachusetts: Ballinger.

Vida, Irena (2007), "Determinants of Consumer Willingness to Purchase Non-Deceptive Counterfeit Products," Managing Global Transitions, 5 (3), 253-70.
Westbrook, Roberts A. and William C. Black (1985), "A Motivation-Based Shopper Typology," Journal of Retailing, 61 (1), 78103.

Wilcox, Keith, Hyeong Min Kim, and Sankar Sen (2009), "Why do consumers buy counterfeit luxury brands?." Journal of Marketing Research, 46 (2), 247-59.

Wilson, Warner R. (1967), "Correlates of avowed happiness," Psychological Bulletin, 67 (4), 294-306. 